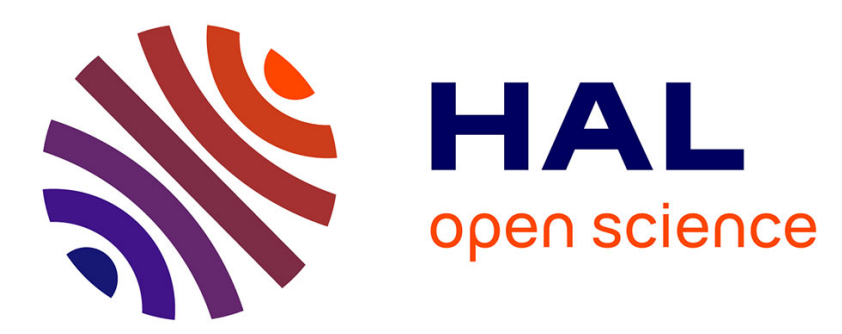

\title{
A Memetic Evolutionary Multi-Objective Optimization Method for Environmental Power Unit Commitment
} Yan-Fu Li, Nicola Pedroni, Enrico Zio

\section{To cite this version:}

Yan-Fu Li, Nicola Pedroni, Enrico Zio. A Memetic Evolutionary Multi-Objective Optimization Method for Environmental Power Unit Commitment. IEEE Transactions on Power Systems, 2013, pp.1-10. hal-00777057

\section{HAL Id: hal-00777057}

https://hal-centralesupelec.archives-ouvertes.fr/hal-00777057

Submitted on 16 Jan 2013

HAL is a multi-disciplinary open access archive for the deposit and dissemination of scientific research documents, whether they are published or not. The documents may come from teaching and research institutions in France or abroad, or from public or private research centers.
L'archive ouverte pluridisciplinaire HAL, est destinée au dépôt et à la diffusion de documents scientifiques de niveau recherche, publiés ou non, émanant des établissements d'enseignement et de recherche français ou étrangers, des laboratoires publics ou privés. 


\title{
A Memetic Evolutionary Multi-Objective Optimization
}

\section{Method for Environmental Power Unit Commitment}

\author{
Y. F. $\mathrm{Li}^{1}$, Member, IEEE, N. Pedroni ${ }^{2}$, E. Zio ${ }^{1,2}$, Senior Member, IEEE
}

\begin{abstract}
A multi-objective power unit commitment problem is framed to consider simultaneously the objectives of minimizing the operation cost and minimizing the emissions from the generation units. To find the solution of the optimal schedule of the generation units, a memetic evolutionary algorithm is proposed, which combines the non-dominated sorting genetic algorithm-II (NSGA-II) and a local search algorithm. The power dispatch sub-problem is solved by the weighed-sum lambdaiteration approach. The proposed method has been tested on systems composed by 10 and 100 generation units for a 24 hour demand horizon. The Pareto-optimal front obtained contains solutions of different trade off with respect to the two objectives of cost and emission, which are superior to those contained in the Pareto-front obtained by the pure NSGA-II. The solutions of minimum cost are shown to compare well with recent published results obtained by single-objective cost optimization algorithms.
\end{abstract}

Index Terms-- power unit commitment, environmental/ economic dispatch, multi-objective optimization, evolutionary algorithm, memetic algorithm, non-dominated sorting genetic algorithm, local search, lambda-iteration approach.

\section{INTRODUCTION}

$\mathrm{T}$ he unit commitment problem (UCP) involves determining the optimal start-up and shut-down schedules of the generation units, and the economic dispatch of the online generators to meet the forecasted demand over a specific short-term time period (e.g. 24 hours) [1]. The classical single-objective UCP aims at minimizing the total operational costs of all generation units, given a number of equality constraints (e.g. system power balances) and inequality constraints (e.g. system spinning reserve requirement, generation limits, minimum up and down times, and ramp rate limits).

The UCP is a large-scale, non-linear, and mixed combinatorial and continuous optimization problem of difficult solution [2]. In the literature, a large number of techniques have been proposed, e.g. priority list [3], dynamic programming [4], branch and bound [5, 6], mixed integer programming [7, 8], Lagrangian relaxation [9, 10], simulated annealing [11], and evolutionary algorithms (EAs) [12-16]. Detailed surveys can be found in $[17,18]$.

However, most existing UCPs are formulated in the form of single-objective optimization to minimize the total operation

${ }^{1}$ Y.F. Li and E. Zio are with the Chair on Systems Science and the Energetic challenge, European Foundation for New Energy-Electricite' de France, at Ecole Centrale Paris and Supelec, Paris, France (e-mail: yanfu.li@ecp.fr, yanfu.li@supelec.fr, enrico.zio@ecp.fr, enrico.zio@supelec.fr ).

${ }^{2}$ N. Pedroni and E. Zio are of the Politecnico di Milano, Milan, Italy (email: nicola.pedroni@mail.polimi.it, enrico.zio@polimi.it) cost $[1,12,14-16,19]$. On the other hand, the increasing awareness of environmental protection is pushing the utilities to improve their design and operational strategies, for reducing the emissions from the power plants [20]. As a result, the consideration of the environmental impacts of power generation in the UCP is receiving intensive research efforts [20-23], particularly by inclusion within the economic dispatch problem (which is a sub-problem included in UCP). To do so, emissions are converted into monetary units through forms of carbon tax or/and emission trading, and then directly included in the total operation cost objective function. However, due to the variations/uncertainties of the electrical market and system behavior, it is often difficult to capture the complicated emission-cost relationships in a single objective function. Alternatively, recent studies on the environmental/ economic dispatch problem (EEDP) are proposing to account for emissions as a separate objective, also to be minimized.

Different approaches have been proposed to tackle the multi-objective EEDP, such as weighted sum [24], $\boldsymbol{\varepsilon}$ constraint [23], and simultaneous optimization [20-22]. The weighted sum approach obtains a set of Pareto-optimal solutions by varying the weights of different objectives. However, this requires a number of runs equal to the number of desired Pareto-optimal solutions. In addition, this method is not able to obtain Pareto-optimal solutions where the problems have non-convex fronts. The $\boldsymbol{\varepsilon}$-constraint method can avoid this difficulty by optimizing the most important objective and treating other objectives as constraints bounded by some allowable levels of $\boldsymbol{\varepsilon}$. These levels are then changed to generate the entire Pareto-optimal solution set. However, this approach is time-consuming and tends to find weakly non-dominated solutions [20].

Recent trends of research have shifted to simultaneous optimization of the separate objectives by dominance, in search of the Pareto-optimal front [25]. Furthermore, some recent works have incorporated the emission objective into the generation scheduling sub-problem [26, 27].

In this study, we merge the multi-objective formulation of the two UCP sub-problems of dispatching and scheduling by including the emission objective into an overall environmental UCP (EUCP), and propose a novel approach to its solution based on memetic algorithms (MAs), an extension of evolutionary algorithm (EAs) which combines heuristics for global search and local search. The approach is tested on two case studies, with 10 and 100 units and a 24 hour horizon.

EAs, especially genetic algorithm (GA) [28], have been shown as powerful techniques for solving multi-objective optimization problems [29]. As extensions, MAs [30] are population-based meta-heuristic search methods combining global search algorithms (e.g. EAs) with local search 
techniques (e.g. Lamarckian local search, tabu search, chaotic search). The rationale behind MAs is that the deficiency of EAs in local exploitation can be compensated by the inclusion of local search techniques which, on their account, are often inadequate in global exploration. MAs have been reported to converge to high quality solutions more efficiently than conventional EAs [31,32]. The success of the multi-objective version of MAs (MOMAs) is dependent on the handling of multiple objectives in the local search and the balance between global search and local search [32]. In this study, we explore two local search strategies (LSSs) equipped with one local search operator (LSO) specifically designed for the UC P.

The rest of this paper is organized as follows: Section II presents the multi-objective formulation of the EUCP; Section III presents the general concept of multi-objective optimization; Section IV describes the proposed MOMA; Section V presents the experiment results and the comparisons to published results; Section VI presents the conclusions of this study and some discussions about future extensions.

\section{MUlti-OBJeCtive Formulation OF THE ENVIRONMENTAL POWER UNIT COMMITMENT PROBLEM}

\section{A. Objective Functions}

The first objective is to minimize the operation cost $f_{c}$ of the $\mathrm{N}$-units system, in arbitrary monetary units [m.u.]. The operation cost includes the fuel cost of the generation unit, the start-up cost and the shut-down cost, over the entire time horizon, usually observed in hours:

$f_{c}=\sum_{i=1}^{N} \sum_{t=1}^{T_{\max }}\left[u_{i}^{t} L C_{i}^{t}+u_{i}^{t}\left(1-u_{i}^{t-1}\right) S_{i}^{t}+u_{i}^{t-1}\left(1-u_{i}^{t}\right) H_{i}\right]$ (m.u.) (1)

where $T_{\max }$ is the total number of hours in the scheduling horizon, $t\left(=1,2, \ldots, T_{\max }\right)$ is the hourly time index, $N$ is the total number of generation units, $i(=1,2, \ldots, N)$ is the generation unit index, $u_{i}^{t}$ is the binary commitment state of unit $i$ at time $t$ ( $u_{i}^{t}=1$ if unit $i$ is committed at time $t ; u_{i}^{t}=0$ otherwise), $L C_{i}^{t}$ is the generation cost of unit $i$ at time $t, S_{i}^{t}$ is the start-up cost of unit $i$ at time $t$, and $H_{i}$ is the shut down cost of unit $i . L C_{i}^{t}$ can be defined as:

$$
L C_{i}^{t}=C_{i}\left(P_{i}^{t}\right)^{2}+B_{i} P_{i}^{t}+A_{i}
$$

where $A_{i}, B_{i}$ and $C_{i}$ are the fuel cost coefficients of unit $i$, and $P_{i}^{t}$ is the actual power output from unit $i$ at time $t$. $S_{i}^{t}$ can be defined as:

$$
S_{i}^{t}=\left\{\begin{array}{c}
S_{i}^{H}, \text { if } T_{i}^{\text {off }} \leq x_{i}^{t, \text { off }} \leq T_{i}^{C}+T_{i}^{\text {off }} \\
S_{i}^{C}, \text { if } x_{i}^{t, \text { off }}>T_{i}^{C}+T_{i}^{\text {off }}
\end{array}\right.
$$

where $x_{i}^{t, o f f}$ is the consecutive time duration when the unit $i$ has been offline just before time $t, T_{i}^{\text {off }}$ is the minimum down time of unit $i, T_{i}^{C}$ is the number of cold-start hours of unit $i$, $S_{i}^{H}$ is the hot-start cost of unit $i$, and $S_{i}^{C}$ is the cold-start cost of unit $i . H_{i}$ is usually modeled as a constant value for each shutdown of each unit.

The second objective function is to minimize the release of air pollutants into the atmosphere [33], $f_{e}$ :

$$
f_{e}=\sum_{i=1}^{N} \sum_{t=1}^{T_{\max }} u_{i}^{t} L E_{i}^{t}(\mathrm{lb})
$$

where $L E_{i}^{t}(\mathrm{lb})$ represents the quantity of pollutants produced by unit $i$ at time $t$ and it is defined as:

$$
L E_{i}^{t}=F_{i}\left(P_{i}^{t}\right)^{2}+E_{i} P_{i}^{t}+D_{i}
$$

where $D_{i}, E_{i}$ and $F_{i}$ are the emission coefficients of unit $i$.

\section{B. Constraints}

1. System power balance: the total power generation at time $t$ equals the total demand. Hence,

$$
\sum_{i=1}^{N} u_{i}^{t} P_{i}^{t}=L^{t}\left(t=1, \ldots, T_{\max }\right)
$$

where $L^{t}$ is the load demand at time $t$.

2. System spinning reserve requirements: a reserve is required to deal with real-time potential sudden load increases due to unexpected demand increase or failure of any of the working units. Hence,

$$
\sum_{i=1}^{N} u_{i}^{t} P_{\max , i} \geq L^{t}+R^{t}\left(t=1, \ldots, T_{\max }\right)
$$

where $R^{t}$ is the system spinning reserve requirement at time $t$, and $P_{\max , i}$ is the rated upper generation limit of unit $i$.

\section{Unit minimum up/down times:}

Minimum up time: $x_{i}^{t, o n} \geq T_{i}^{o n}(i=1, \ldots, N)$

Minimum down time: $x_{i}^{t, o f f} \geq T_{i}^{\text {off }}(i=1, \ldots, N)$

where $x_{i}^{t, o n}$ is the consecutive time duration when the unit $i$ has been online just before time $t, T_{i}^{o n}$ is the minimum up time of unit $i$.

4. Unit generation limits: for stable operation, the power output of each generation unit must fall into a region of operation defined by lower and upper limits:

$$
P_{\max , i} \geq P_{i}^{t} \geq P_{\min , i}(i=1, \ldots, N)
$$

where $P_{\min , i}$ is the rated lower generation limit of unit $i$.

5. Ramp-rate limits: due to the mechanical characteristics and thermal stress limitations of each unit, the power output of each unit is restricted by its ramp-rate limits:

$$
\begin{aligned}
R_{i}^{U} \geq & P_{i}^{t}-P_{i}^{t-1} \geq-R_{i}^{D} \\
& \left(i=1, \ldots, N ; t=1, \ldots, T_{\max }\right)
\end{aligned}
$$

where $R_{i}^{U}$ and $R_{i}^{D}$ are the ramp-up and ramp-down limits of unit $i$, respectively.

EUCP can be formulated as a non-linear mixed combinatorial and continuous multi-objective optimization problem, as follows:

$$
\begin{array}{cl}
\text { Minimize } & {\left[f_{c}(\boldsymbol{P}, \boldsymbol{U}), f_{e}(\boldsymbol{P}, \boldsymbol{U})\right]} \\
\text { Subject to: } & g(\boldsymbol{P})=0 \\
& h(\boldsymbol{P}, \boldsymbol{U}) \leq 0
\end{array}
$$

where $\boldsymbol{P}=\left(P_{1}^{1}, P_{2}^{1}, \ldots, P_{N}^{1} ; \ldots ; P_{1}^{T_{\max }}, P_{2}^{T_{\max }}, \ldots, P_{N}^{T_{\max }}\right)$ is a $N \times T_{\max }$ matrix with the powers $P_{i}^{t}$ as its elements and $\boldsymbol{U}=\left(u_{1}^{1}, u_{2}^{1}, \ldots, u_{N}^{1} ; \ldots ; u_{1}^{T_{\max }}, u_{2}^{T_{\max }}, \ldots, u_{N}^{T_{\max }}\right)$ is a $N \times T_{\max }$ matrix with the commitment states $u_{i}^{t}$ as its elements.

\section{Multi-OBJective Optimization}

Many real world applications involve simultaneous optimization of several objective functions, which are often competing or/and conflicting with each other, and subject to a number of equality and inequality constraints. In general, these multi-objective problems can be formulated as follows:

$$
\begin{array}{lll}
\text { Minimize } & f_{o}(\boldsymbol{U}), o=1, \ldots, O \\
\text { Subject to: } & \begin{cases}g_{j}(\boldsymbol{U})=0, & j=1, \ldots, J \\
h_{k}(\boldsymbol{U}) \leq 0, & k=1, \ldots, K\end{cases}
\end{array}
$$

where $f_{o}$ is the oth objective function, $\boldsymbol{U}$ is a decision vector that represents a solution, $O$ is the number of objectives, $g_{j}$ is the $j$-th of the $J$ equality constraints and $h_{k}$ is the $k$-th of the $K$ 
inequality constraints. The objective functions $f_{o}(\boldsymbol{U})$ must be evaluated in correspondence of each decision variable vector $\boldsymbol{U}$ in the search space. The final goal is to identify a set of optimal decision variable vectors $\boldsymbol{U}_{m}^{*}, m=1,2, \ldots, M$, instead of a single optimal solution. In this set of optimal solutions, no one can be regarded to be better than any other with respect to all the objective functions. The comparison of solutions may be achieved in terms of the concepts of Pareto optimality and dominance [34]: taking a minimization problem as example, solution $\boldsymbol{U}_{a}$ is regarded to dominate solution $\boldsymbol{U}_{b}\left(\boldsymbol{U}_{a}>\boldsymbol{U}_{b}\right)$ if both following conditions are satisfied:

$$
\begin{array}{r}
\forall j \in\{1,2, \ldots, O\}, f_{j}\left(\boldsymbol{U}_{a}\right) \leq f_{j}\left(\boldsymbol{U}_{b}\right) \\
\exists k \in\{1,2, \ldots, O\}, f_{k}\left(\boldsymbol{U}_{a}\right)<f_{k}\left(\boldsymbol{U}_{b}\right)
\end{array}
$$

If any of the above two conditions is violated, the solution $\boldsymbol{U}_{a}$ does not dominate the solution $\boldsymbol{U}_{b}$, and $\boldsymbol{U}_{b}$ is said to be nondominated by $\boldsymbol{U}_{a}$. The solutions that are nondominated within the entire search space are denoted as Pareto-optimal and constitute the Pareto-optimal set, and the corresponding values of the objective functions form the so called Paretooptimal front in the objective functions space. The goal of a multi-objective optimization algorithm is to guide the search for finding solutions of the Pareto-optimal set.

\section{Proposed Multi-ObJective Memetic Algorithm}

MAs perform global exploration by EA and local exploitation by a local search algorithm, in a balanced way [32]. In this Section, we first present a two-stage global search algorithm composed of a multi-objective EA (MOEA) for the generation scheduling problem and a weighted-sum lambda-iteration algorithm [35] for the environmental/economic dispatch problem (EEDP). Then, we propose a local search algorithm which dynamically switches on/off the units according to their performance with respect to the two objectives of cost and emission.

\section{A. EA for multi-objective global exploration}

Genetic algorithms [28] are the most popular MOEAs. We use NSGA-II [36], which has become a standard approach with three advantages over NSGA: (i) denoting by $N_{\text {pop }}$ the number of candidate solutions (chromosomes) in the population, NSGA-II has $O\left(O N_{\text {pop }}^{2}\right.$ computational complexity while NSGA has $O\left(O N_{\text {pop }}^{3}\right)$, (ii) NSGA-II includes elitism while NSGA does not, and (iii) NSGA-II ensures selfmaintained diversity while NSGA uses a predefined sharing parameter to control diversity. Detailed information regarding NSGA-II can be found in [36].

\section{$i$. Encoding and initial population generation}

The solution to the UCP consists of two parts: the on-off schedule, $u_{i}^{t}$, of each unit $i$ at each hour $t$; the power, $P_{i}^{t}$ (continuous values), generated by each unit $i$ at each hour $t$. In our approach, the on-off schedule $u_{i}^{t}$ is identified through the global search by NSGA-II, and then the optimal values of $P_{i}^{t}$ are found by a weighted-sum lambda-iteration method for solving the EEDP with fixed schedule. In the population, the decision variables are coded as a binary string $\boldsymbol{U}=$ $\left(u_{1}^{1} u_{2}^{1} \ldots u_{N}^{1} \ldots u_{1}^{T_{\max }} u_{2}^{T_{\max }} \ldots u_{N}^{T_{\max }}\right)$ where $N$ is the total number of generation units and $T_{\max }$ is the number of hours in the scheduling horizon (e.g. equal to 24). The initial population of $N_{\text {pop }}$ chromosomes of the NSGA-II for solving the on-off schedule, is generated by the priority list (PL) method [19], which is efficient against the fact that the UCP is heavily constrained so that the purely random generation of the initial population could result to final solutions of low quality [3].

To preserve the diversity of solutions, two types of PLs (namely, cost-based PL and emission-based PL) are considered for generating the initial population. In the costbased (or emission-based) PL, all generation units are located in the ascending order of their average full load costs (AFLCs) (or average full load emissions (AFLEs)). At the bottom of the cost-based (or emission-based) PL is the unit with the lowest AFLC (or AFLE), which indicates the highest priority for commitment. Two primary solutions are generated by committing the units in the order of their cost-based (or emission-based) priority ranks (denoted by $R_{c}\left(u_{i}\right)$ or $R_{e}\left(u_{i}\right)$ ) until the total maximum power output exceeds the load demand plus the spinning reserve requirements at each time interval. In case that the two units have equal priority, the sequence of their commitments is randomly determined. The variant solutions are generated by randomly turning on up to 3 units ranked immediately after the units in the primary solutions at each time interval. Half of the entire population is generated from cost-based PL and half from the emissionbased PL. Figure 1 shows a candidate initial solution.

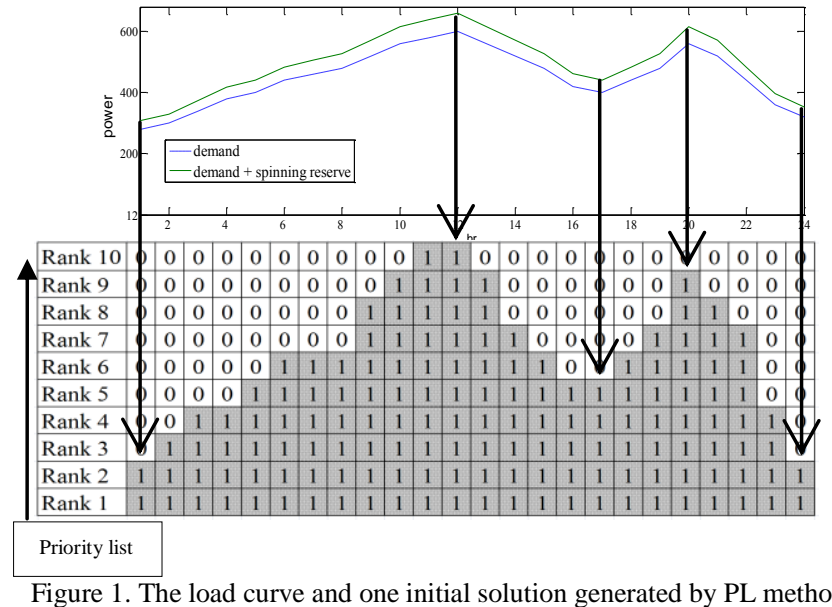

\section{ii. Fitness functions and EEDP}

The fitness functions are built with the inclusion of penalty functions for constraint handling. In the penalty function method, we combine the inequality constraint conditions in (7-9) into the objective functions (1) and (4), respectively, using penalty parameters as follows:

$$
\begin{gathered}
g_{o}=f_{o}(\boldsymbol{P}, \boldsymbol{U})+\alpha \cdot L P \\
L P=\left\{\sum_{t=1}^{T_{\max }} \max \left[0, L^{t}-\sum_{i=1}^{N} u_{i}^{t} P_{i}^{t}\right]+\right. \\
\left.\sum_{t=1}^{T_{\max }} \max \left[0, L^{t}+R^{t}-\sum_{i=1}^{N} u_{i}^{t} P_{\max , i}\right]\right\}
\end{gathered}
$$

where $L P$ is the penalty due to the unmet load, $\alpha$ is the predefined penalty constant with units $\$ / \mathrm{MWh}$, and $O$ is the total number of objective functions (in case of EUCP, $O=2$ ). The constraints in (10), i.e. the unit generation limits, are handled in lambda-iteration method. 
To obtain the fitness value corresponding to a binary vector $\boldsymbol{U}$, the optimal values of the continuous vector $\boldsymbol{P}$ need to be determined by solving the $T_{\max }$ number of different EEDPs. Because the EEDP has two objectives, the weighted-sum approach [24] is used to aggregate the objectives for the implementation of the lambda-iteration method (with complexity $O(N)$ ). The weighted-sum fitness function (with fixed values of $\boldsymbol{U}$ ) has the following form:

$$
g(\boldsymbol{P})=\sum_{o=1}^{O} \eta_{o} \cdot g_{o}(\boldsymbol{P})
$$

where $\boldsymbol{\eta}=\left(\eta_{1}, \ldots, \eta_{0}\right)$ is a vector of random weight values such that their sum is equal to 1 . It should be noted that the real-valued vector $\boldsymbol{P}$ of EEDP can be integrated into the encoding scheme of MOEA for a simultaneous optimization. However, this approach might double the size of each individual solution in the population, thus significantly expanding the search space of the MOEA. Since the efficiency of the global search algorithm is a primary concern for large problem dimensions, we propose to use the weighted-sum lambda-iteration method for the EEDP. Introducing a Lagrange multiplier $\lambda_{t}$, the EEDP at hour $t$ for unit $i=1, \ldots, N$ can be written as:

$$
\frac{\partial}{\partial P_{i}^{t}}\left\{\sum_{i=1}^{N}\left[\eta_{1} L C_{i}^{t}\left(P_{i}^{t}\right)+\eta_{2} L E_{i}^{t}\left(P_{i}^{t}\right)\right]+\lambda_{t}\left[L^{t}-\sum_{i=1}^{N} P_{i}^{t}\right]\right\} u_{i}^{t}=0
$$

where $\eta_{1}$ and $\eta_{2}$ are the weights for the two objective functions. At each generation of NSGA-II, a new set of weights are generated according to their definition in (20). Then the standard lambda-iteration algorithm is applied to solve the system of $N$ equations to obtain the solution vector of powers $P_{i}^{t}, i=1, \ldots, N$.

\section{iii. Non-dominated sorting and genetic operators}

At a given search iteration (generation), the (parent) population is evaluated by a fast non-dominated sorting algorithm [36], which divides it into different Pareto frontiers by assigning to each chromosome of the population a rank equal to its non-domination level (e.g. 1 is the best, 2 is the second best, etc). First the top rank 1 is assigned to all the non-dominated solutions in the current population; then, the top rank solutions are temporarily removed from the current population and the second top rank is assigned to all the nondominated solutions in the remaining population, and so on. On the results of the non-dominated sorting of the parent population, the binary tournament selection with replacement, cross-over, and mutation operators are applied to create the offspring population, still of size $N_{\text {pop }}$.

\section{iv. Elitism mechanism}

This operation involves two major steps: 1) create a union of $2 N_{\text {pop }}$ chromosomes by combining parent and offspring populations, and sort the chromosomes in the union by a fast non-dominated sorting algorithm; 2) select the first $N_{p o p}$ chromosomes from the union to form a new parent population. The crowding distance measure is used in this step to compare the chromosomes with the same rank (a more 'crowded' chromosome has lower priority than a less 'crowded' one), where crowding refers to the density of solutions present in a neighborhood of specified radius [36].

\section{B. Local Search Algorithm (LSA)}

Local search (LS) can enhance the search capability of EAs by carrying out local exploitation, provided that the global and local searches are well-balanced. In this Section, we utilize two local search strategies (LSSs) equipped with one local search operator (LSO) specifically designed for the UCP.

At each local search run, the LSO is applied to shut down or turn on a number of units located at the 'boundaries' of the schedules (as shown in Fig. 2) with a probability related to the AFLC rank $R_{c}\left(u_{i}\right)$ (or AFLE rank $R_{e}\left(u_{i}\right)$ ) of the units. It is noted that the units are ranked in ascending order of the rate values (e.g. the unit with lowest cost rate ranks $1^{\text {st }}$ in the cost rate ranking list). If unit $i$ has the relationship $\frac{R_{C}\left(u_{i}\right)-k}{N}>$ $\operatorname{rand}(0,1)$ or $\frac{R_{e}\left(u_{i}\right)-k}{N}>\operatorname{rand}(0,1)$ (where $N$ is the total number of units, $k$ is a parameter that controls the probability of the unit undergoing local search, and $\operatorname{rand}(0,1)$ is a uniform rand value in $[0,1)$ ) satisfied, then all the ' 01 ' and ' 10 ' combinations located at the boundaries (their number is denoted by $n_{c}$ ) are subject to mutation with equal probability $1 / n_{c}$. For each of the combinations eligible for mutation, it becomes ' 00 ' or ' 11 ' with probability equal to 0.5 .

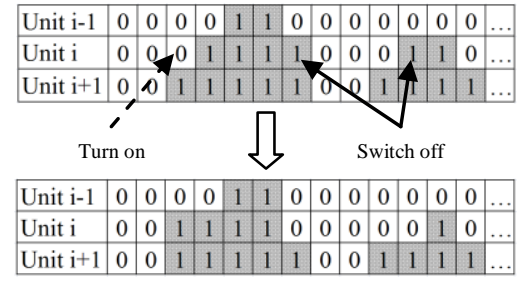

Figure 2. The local search operator

By the application of LSO to the schedule of each unit, a new vector solution $\boldsymbol{U}_{c}^{\prime}$ is generated which replaces the current one $\boldsymbol{U}_{c}$ only if it dominates.

The algorithm design involves also the selection of the individuals undergoing local search and the length of the local search. In our LSA, we consider two LSSs, namely wide LS (WLS) and deep LS (DLS) to be combined with the global search algorithm separately. The former applies the LSO only one time onto all the $N_{p o p}$ solutions in the population, whereas the latter selects the individual with best weightedsum of the fitness values (in eq.(20)) at each generation to be the initial solution, and then performs $N_{\text {pop }}$ times the LSO at each iteration.

\section{Minimum Up/Down Constraints Handling}

The minimum up/down constraints are handled by the heuristic procedure coded below [15]:

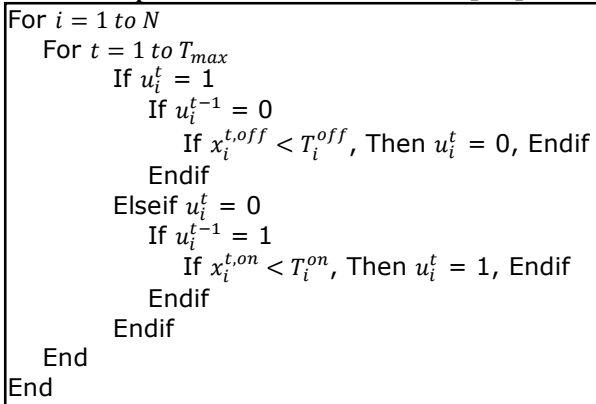


where $x_{i}^{t, o n}$ and $x_{i}^{t, o f f}$ are the consecutive time duration when the unit $i$ has been online/offline just before time $t$, respectively. This procedure is executed before performing the weighted-sum lambda-iteration method to solve the EEDP.

\section{Computational Flow}

The computational flow of the proposed MOMA (NSGAII+LSA) is given in Figure 3.

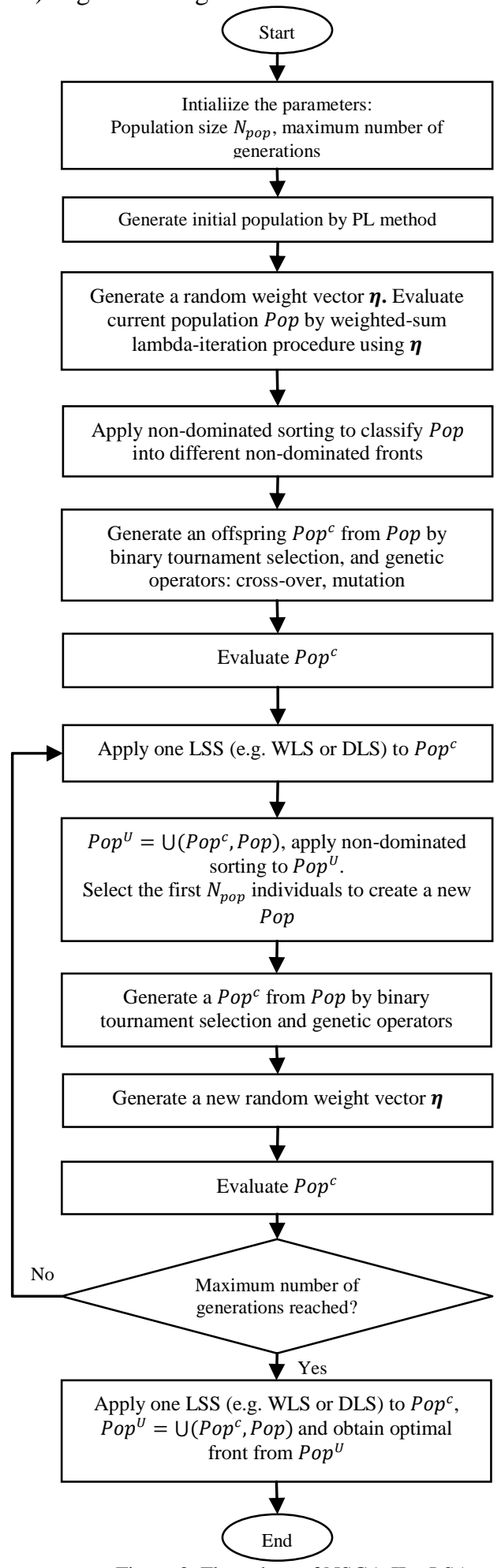

Figure 3. Flow chart of NSGA-II + LSA

\section{EXPERIMENT DESIGN AND RESULTS}

In this Section, the proposed MOMA search is tested on UCPs of two different sizes: a classical 10-unit system of literature [37] and a 100-unit system, with a time horizon of 24 hours. The operation data and demand data of the 10-unit system are shown in Tables I and II, respectively. Table I summarizes the coefficients of power output limits and cost functions, taken from [37], and the coefficients of emission functions taken from [33]. Table II shows the load demand values, taken from [37]. The spinning reserve is assumed to be $10 \%$ of the demand. The 100-unit system is artificially created by duplicating the operation data of the 10-unit system 9 times and increasing the load demand value at each hour by 9 times. It is noted that the ramp rate limits are not included in these case studies. However, the proposed algorithm is able to handle this type of constraint by adding a penalty onto the weighted-sum of the objective functions in the economic dispatch sub-problem.

TABLE I. OPERATION DATA FOR OF THE 10-UNIT SYSTEM

\begin{tabular}{|c|c|c|c|c|c|c|c|c|c|c|}
\hline Unit & 1 & 2 & 3 & 4 & 5 & 6 & 7 & 8 & 9 & 10 \\
\hline $\begin{array}{r}P_{\max } \\
(\mathrm{MW}) \\
\end{array}$ & 455 & 455 & 130 & 130 & 162 & 80 & 85 & 55 & 55 & 55 \\
\hline $\begin{array}{r}P_{\min } \\
(\mathrm{MW}) \\
\end{array}$ & 150 & 150 & 20 & 20 & 25 & 20 & 25 & 10 & 10 & 10 \\
\hline \multicolumn{11}{|c|}{ Cost function coefficients } \\
\hline$A$ & 1000 & 970 & 700 & 680 & 450 & 370 & 480 & 660 & 665 & 670 \\
\hline$B$ & 16.19 & 17.26 & 16.6 & 16.5 & 19.7 & 22.2 & 27.74 & 25.9 & 27.2 & 27.79 \\
\hline$C$ & $\begin{array}{c}0.0004 \\
8\end{array}$ & $\begin{array}{c}0.0003 \\
1\end{array}$ & 0.002 & 0.00211 & 0.00398 & $\begin{array}{c}0.0071 \\
2\end{array}$ & 0.00079 & \begin{tabular}{|c|}
0.0041 \\
3
\end{tabular} & $\begin{array}{c}0.0022 \\
2\end{array}$ & $\begin{array}{c}0.0017 \\
3\end{array}$ \\
\hline \begin{tabular}{|c|}
$T^{\text {on }}$ \\
$(\mathrm{Hr})$
\end{tabular} & 8 & 8 & 5 & 5 & 6 & 3 & 3 & 1 & 1 & 1 \\
\hline \begin{tabular}{|c}
$\mathrm{T}^{\text {off }}$ \\
$(\mathrm{Hr})$
\end{tabular} & 8 & 8 & 5 & 5 & 6 & 3 & 3 & 1 & 1 & 1 \\
\hline$S^{H}(\$)$ & 4500 & 5000 & 550 & 560 & 900 & 170 & 260 & 30 & 30 & 30 \\
\hline$S^{C}(\$)$ & 9000 & 10000 & 1100 & 1120 & 1800 & 340 & 520 & 60 & 60 & 60 \\
\hline$T^{C}(\mathrm{Hr})$ & 5 & 5 & 4 & 4 & 4 & 2 & 2 & 0 & 0 & 0 \\
\hline \begin{tabular}{|l|} 
Initial \\
state \\
$(\mathrm{Hr})$ \\
\end{tabular} & 8 & 8 & -5 & -5 & -6 & -3 & -3 & -1 & -1 & -1 \\
\hline \multicolumn{11}{|c|}{ Emission function coefficients } \\
\hline$D$ & 42.90 & 42.90 & 40.27 & 40.27 & 13.86 & 13.86 & 330.00 & 330.00 & 350.00 & 360.00 \\
\hline$E$ & -0.5112 & -0.5112 & 0.5455 & -0.5455 & 0.3277 & 0.3277 & -3.9023 & -3.9023 & -3.9524 & -3.9864 \\
\hline$F$ & 0.0046 & 0.0046 & 0.0068 & 0.0068 & 0.0042 & 0.0042 & 0.0465 & 0.0465 & 0.0465 & 0.0470 \\
\hline
\end{tabular}

TABLE II. DEMAND DATA ON 24 HOUR TIME HORIZON

\begin{tabular}{|l|l|l|l|l|l|l|l|}
\hline $\mathrm{Hr}$ & $\begin{array}{l}\text { Demand } \\
(\mathrm{MW})\end{array}$ & $\mathrm{Hr}$ & $\begin{array}{l}\text { Demand } \\
(\mathrm{MW})\end{array}$ & $\mathrm{Hr}$ & $\begin{array}{l}\text { Demand } \\
(\mathrm{MW})\end{array}$ & $\mathrm{Hr}$ & $\begin{array}{l}\text { Demand } \\
(\mathrm{MW})\end{array}$ \\
\hline 1 & 700 & 7 & 1150 & 13 & 1400 & 19 & 1200 \\
\hline 2 & 750 & 8 & 1200 & 14 & 1300 & 20 & 1400 \\
\hline 3 & 850 & 9 & 1300 & 15 & 1200 & 21 & 1300 \\
\hline 4 & 950 & 10 & 1400 & 16 & 1050 & 22 & 1100 \\
\hline 5 & 1000 & 11 & 1450 & 17 & 1000 & 23 & 900 \\
\hline 6 & 1100 & 12 & 1500 & 18 & 1100 & 24 & 800 \\
\hline
\end{tabular}

Three EAs are applied in the experiments: pure NSGA-II, NSGA-II+DLS, and NSGA-II+WLS. The parameters of NSGA-II are set as follows: 1) the maximum generation and the population size are $50 \times N$ and 50, respectively, as suggested in [37]; 2) 0.5 to 1 with step size 0.1 , and the mutation probability changes from 0.01 to 0.05 with step size 0.01 . The possible combinations of these two probabilities are tested on the 10-unit system: the best combination is found to be 0.9 for crossover probability and 0.01 for mutation probability, and is retained for all numerical evaluations. In the two MOMAs, the number of local searches and the population size are set to 10 , so to have the same number of optimal dispatch evaluations as the pure NSGA-II. The rest of the parameters of the MOMAs are identical to those of 
NSGA-II. Because genetic algorithms are stochastic, in the comparative study each algorithm is run 20 times. Since solving EEDP is the most time-consuming step in the algorithm, it is only performed if the given unit commitment schedule satisfies the spinning reserve constraint.

All the experiments have been carried out in MATLAB on a PC with Intel Core i5 of $3.4 \mathrm{GHz}$ and $4 \mathrm{~GB}$ RAM.

\section{A. Convergence Property and Single-Objective Performance Comparison}

The convergence plots of the algorithms applied to the 10-unit system are shown in Fig 4. The data reported are the minimum operation cost and emission values in the Pareto-front at each generation during the search. It is observed that in general the MOMAs converge faster than the NSGA-II.
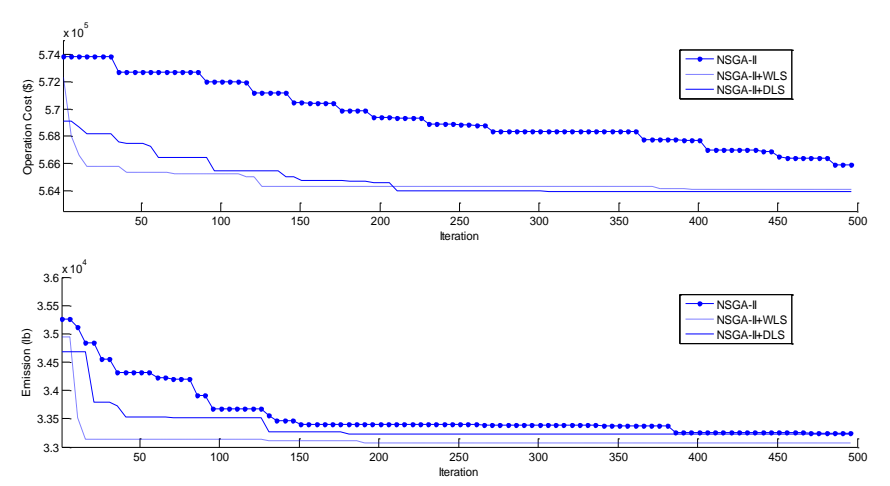

Figure 4. Convergence plots of the competing algorithms

Table III presents the best, average and worst solutions of minimum cost out of the 20 runs of the MOEA algorithms, on the 10-unit and 100-unit systems, respectively. The MOMAs appear to be more robust, on average. Their performance compare well also with the published results, reported in Table IV. The best, average and worse computation times of each method are also presented in Table III. It can be seen that the methods have similar computation times due to the fact that the number of fitness evaluations is the same for each method.

TABLE III. COST OPTIMIZATION RESULTS OF MOMAS AND NSGA-II
\begin{tabular}{|c|c|c|c|c|}
\hline No of Units & Cost (\$) & NSGA-II & NSGA-II + DLS & NSGA-II + WLS \\
\hline 10 & Best & 565898 & $\mathbf{5 6 3 9 3 8}$ & 564114 \\
\hline & Average & 567212 & 564240 & 564554 \\
\hline & Worst & 569923 & 564723 & 565296 \\
\hline 100 & Best & 5625616 & $\mathbf{5 6 0 5 9 1 8}$ & 5618657 \\
\hline & Average & 5627331 & 5611614 & 5624631 \\
\hline & Worst & 5634676 & 5617595 & 5632097 \\
\hline No of Units & Time & NSGA-II & NSGA-II + DLS & NSGA-II + WLS \\
& (Sec) & & & 82 \\
\hline 10 & Best & 83 & 80 & 86 \\
\hline & Average & 85 & 82 & 93 \\
\hline & Worst & 90 & 87 & 3454 \\
\hline 100 & Best & 3603 & 3484 & 4326 \\
\hline & Average & 4354 & 4254 & 4530 \\
\hline & Worst & 4708 & 4639 & \\
\hline
\end{tabular}

Table IV presents the best solutions obtained by the NSGAII+DLS and the comparison to the solutions obtained with the single-objective optimization methods of the literature [10-12, 37-39]. It is shown that the NSGA-II+DLS is able to achieve results comparable to the best ones of the published work.
TABLE IV. COMPARISONS WITH PUBLISHED BEST RESUltS OF SINGLE OBJECTIVE COST OPTIMIZATION

\begin{tabular}{|c|c|c|}
\hline Methods & 10 -unit & 100 -unit \\
\hline ELR [10] & 563977 & 5605678 \\
\hline GA [37] & 565825 & 5627437 \\
\hline SA [11] & 565828 & 5617876 \\
\hline UCC-GA [38] & 563977 & 5626514 \\
\hline QEA-UC [12] & 563938 & 5609550 \\
\hline ICA [39] & 563938 & 5617913 \\
\hline NSGA-II+DLS & $\mathbf{5 6 3 9 3 8}$ & $\mathbf{5 6 0 5 9 1 8}$ \\
\hline
\end{tabular}

The commitment schedule, power dispatch, fuel and startup costs, and emissions of the best minimum-cost solution obtained by NSGA-II+DLS on the 10-unit system are presented in Table $\mathrm{V}$. Note that the total operation cost obtained by NSGA-II+DLS presented in Table IV is the sum of the total fuel cost and the total start-up cost presented in Table V.

TABle V. Minimum Cost Solution: Schedule and Dispatch, AND CORRESPONDING COSTS AND EMISSIONS FOR THE 10-UNIT SYSTEM

\begin{tabular}{|c|c|c|c|c|c|c|c|c|c|c|c|c|c|}
\hline \multirow{2}{*}{$\mathrm{Hr}$} & \multicolumn{10}{|c|}{ Generation units } & \multirow{2}{*}{$\begin{array}{l}\text { Fuel } \\
\text { cost (\$) }\end{array}$} & \multirow{2}{*}{$\begin{array}{l}\text { Start-up } \\
\text { cost (\$) }\end{array}$} & \multirow{2}{*}{$\begin{array}{l}\text { Emission } \\
\text { (lb) }\end{array}$} \\
\hline & 1 & 2 & 3 & 4 & 5 & 6 & 7 & 8 & 9 & 10 & & & \\
\hline 1 & 455 & 245 & 0 & 0 & b & 0 & 0 & 0 & 0 & 0 & 13683 & 0 & 956 \\
\hline 2 & 455 & 295 & 0 & 0 & b & 0 & 0 & 0 & 0 & 0 & 14555 & 0 & 1055 \\
\hline 3 & 455 & 370 & 0 & 0 & 25 & 0 & 0 & 0 & 0 & 0 & 16809 & 900 & 1271 \\
\hline 4 & 455 & 455 & 0 & 0 & 40 & 0 & 0 & 0 & 0 & 0 & 18598 & 0 & 1559 \\
\hline 5 & 455 & 390 & 0 & 130 & 25 & 0 & 0 & 0 & 0 & 0 & 20020 & 560 & 1415 \\
\hline 6 & 455 & 360 & 130 & 130 & 25 & 0 & 0 & 0 & 0 & 0 & 22387 & 1100 & 1553 \\
\hline 7 & 455 & 410 & 130 & 130 & 25 & 0 & 0 & 0 & 0 & 0 & 23262 & 0 & 1704 \\
\hline 8 & 455 & 455 & 130 & 130 & 30 & 0 & 0 & 0 & 0 & 0 & 24150 & 0 & 1863 \\
\hline 9 & 455 & 455 & 130 & 130 & 85 & 20 & 25 & 0 & 0 & 0 & 27251 & 860 & 2191 \\
\hline 10 & 455 & 455 & 130 & 130 & 162 & 33 & 25 & 10 & 0 & 0 & 30058 & 60 & 2599 \\
\hline 11 & 455 & 455 & 130 & 130 & 162 & 73 & 25 & 10 & 10 & 0 & 31916 & 60 & 2945 \\
\hline 12 & 455 & 455 & 130 & 130 & 162 & 80 & 25 & 43 & 10 & 10 & 33890 & 60 & 3229 \\
\hline 13 & 455 & 455 & 130 & 130 & 162 & 33 & 25 & 10 & 0 & 0 & 30058 & 0 & 2599 \\
\hline 14 & 455 & 455 & 130 & 130 & 85 & 20 & 25 & 0 & 0 & 0 & 27251 & 0 & 2191 \\
\hline 15 & 455 & 455 & 130 & 130 & 30 & 0 & 0 & 0 & 0 & 0 & 24150 & 0 & 1863 \\
\hline 16 & 455 & 310 & 130 & 130 & 25 & 0 & 0 & 0 & 0 & 0 & 21514 & 0 & 1424 \\
\hline 17 & 455 & 260 & 130 & 130 & 25 & 0 & 0 & 0 & 0 & 0 & 20642 & 0 & 1319 \\
\hline 18 & 455 & 360 & 130 & 130 & 25 & 0 & 0 & 0 & 0 & 0 & 22387 & 0 & 1553 \\
\hline 19 & 455 & 455 & 130 & 130 & 30 & 0 & 0 & 0 & 0 & 0 & 24150 & 0 & 1863 \\
\hline 20 & 455 & 455 & 130 & 130 & 162 & 33 & 25 & 10 & 0 & 0 & 30058 & 490 & 2599 \\
\hline 21 & 455 & 455 & 130 & 130 & 85 & 20 & 25 & 0 & 0 & 0 & 27251 & 0 & 2191 \\
\hline 22 & 455 & 455 & 0 & 0 & 145 & 20 & 25 & 0 & 0 & 0 & 22736 & 0 & 1959 \\
\hline 23 & 455 & 425 & 0 & 0 & p & 20 & 0 & 0 & 0 & 0 & 17645 & 0 & 1441 \\
\hline 24 & 455 & 345 & 0 & 0 & b & 0 & 0 & 0 & 0 & 0 & 15428 & 0 & 1177 \\
\hline Total & 10920 & 9685 & 2080 & 2210 & 1515 & 352 & 225 & 83 & 20 & 10 & 559848 & 4090 & 44520 \\
\hline
\end{tabular}

The best, average and worst solutions of minimum emission out of the 20 runs of the MOEAs are presented in Table VI. The details of the best solution found by NSGA-II+WLS on 10 -unit system are presented in Table VII. Comparing to the solution presented in Table $\mathrm{V}$, units 4,5 and 6 have much higher power outputs and units 1 and 2 have much lower power outputs. This is due to the fact that they have different AFLC and AFLE ranks, i.e. units 1, 2, 4, 5, and 6 rank 1, 2, 3, 5 , and 6 in terms of AFLC, whereas they rank 4, 5, 6, 1, and 3 in terms of AFLE.

TABLE VI. EMISSION OPTIMIZATION RESULTS OF MOMAS AND NSGA-II

\begin{tabular}{|c|c|c|c|c|}
\hline $\begin{array}{c}\text { No of } \\
\text { Units }\end{array}$ & $\begin{array}{c}\text { Emission } \\
(\mathrm{Ib})\end{array}$ & NSGA-II & $\begin{array}{c}\text { NSGA-II + } \\
\text { DLS }\end{array}$ & $\begin{array}{c}\text { NSGA-II + } \\
\text { WLS }\end{array}$ \\
\hline 10 & Best & 33192 & 33329 & $\mathbf{3 3 0 6 2}$ \\
\hline & Average & 33814 & 33777 & 33529 \\
\hline & Worst & 34578 & 34174 & 34070 \\
\hline 100 & Best & 344379 & $\mathbf{3 2 9 9 3 8}$ & 342947 \\
\hline & Average & 346982 & 341065 & 349578 \\
\hline & Worst & 352123 & 344560 & 357974 \\
\hline
\end{tabular}


TABLE VII. Minimum EMISSION SOLUTION: SCHEDULE AND DisPATCH, AND CORRESPONDING COSTS AND EMISSIONS FOR THE 10-UNIT SYSTEM

\begin{tabular}{|c|c|c|c|c|c|c|c|c|c|c|c|c|c|}
\hline \multirow{2}{*}{$\mathrm{Hr}$} & \multicolumn{10}{|c|}{ Generation units } & \multirow{2}{*}{$\begin{array}{l}\text { Fuel } \\
\text { cost (\$) }\end{array}$} & \multirow{2}{*}{$\begin{array}{l}\text { Start-up } \\
\text { cost (\$) }\end{array}$} & \multirow{2}{*}{$\begin{array}{l}\text { Emissior } \\
\text { (lb) }\end{array}$} \\
\hline & 1 & 2 & 3 & 4 & 5 & 6 & 7 & 8 & 9 & 10 & & & \\
\hline 1 & 216 & 216 & 0 & 130 & 137 & 0 & 0 & 0 & 0 & 0 & 15334 & 0 & 518 \\
\hline 2 & 207 & 207 & 0 & 130 & 127 & 80 & 0 & 0 & 0 & 0 & 16983 & 170 & 541 \\
\hline 3 & 217 & 217 & 69 & 130 & 138 & 80 & 0 & 0 & 0 & 0 & 19404 & 550 & 696 \\
\hline 4 & 245 & 245 & 88 & 130 & 162 & 80 & 0 & 0 & 0 & 0 & 21192 & 0 & 857 \\
\hline 5 & 264 & 264 & 101 & 130 & 162 & 80 & 0 & 0 & 0 & 0 & 22039 & 0 & 948 \\
\hline 6 & 301 & 301 & 126 & 130 & 162 & 80 & 0 & 0 & 0 & 0 & 23736 & 0 & 1157 \\
\hline 7 & 324 & 324 & 130 & 130 & 162 & 80 & 0 & 0 & 0 & 0 & 24585 & 0 & 1275 \\
\hline 8 & 349 & 349 & 130 & 130 & 162 & 80 & 0 & 0 & 0 & 0 & 25435 & 0 & 1404 \\
\hline 9 & 363 & 363 & 130 & 130 & 162 & 80 & 72 & 0 & 0 & 0 & 28396 & 520 & 1772 \\
\hline 10 & 384 & 384 & 130 & 130 & 162 & 80 & 74 & 55 & 0 & 0 & 31283 & 60 & 2159 \\
\hline 11 & 382 & 382 & 130 & 130 & 162 & 80 & 74 & 55 & 55 & 0 & 33367 & 60 & 2417 \\
\hline 12 & 379 & 379 & 130 & 130 & 162 & 80 & 74 & 55 & 55 & 55 & 35483 & 60 & 2685 \\
\hline 13 & 384 & 384 & 130 & 130 & 162 & 80 & 74 & 55 & 0 & 0 & 31283 & 0 & 2159 \\
\hline 14 & 363 & 363 & 130 & 130 & 162 & 80 & 72 & 0 & 0 & 0 & 28396 & 0 & 1772 \\
\hline 15 & 349 & 349 & 130 & 130 & 162 & 80 & 0 & 0 & 0 & 0 & 25435 & 0 & 1404 \\
\hline 16 & 282 & 282 & 113 & 130 & 162 & 80 & 0 & 0 & 0 & 0 & 22887 & 0 & 1048 \\
\hline 17 & 264 & 264 & 101 & 130 & 162 & 80 & 0 & 0 & 0 & 0 & 22039 & 0 & 948 \\
\hline 18 & 301 & 301 & 126 & 130 & 162 & 80 & 0 & 0 & 0 & 0 & 23736 & 0 & 1157 \\
\hline 19 & 349 & 349 & 130 & 130 & 162 & 80 & 0 & 0 & 0 & 0 & 25435 & 0 & 1404 \\
\hline 20 & 384 & 384 & 130 & 130 & 162 & 80 & 74 & 55 & 0 & 0 & 31283 & 320 & 2159 \\
\hline 21 & 363 & 363 & 130 & 130 & 162 & 80 & 72 & 0 & 0 & 0 & 28396 & 0 & 1772 \\
\hline 22 & 277 & 277 & 110 & 130 & 162 & 80 & 64 & 0 & 0 & 0 & 24907 & 0 & 1290 \\
\hline 23 & 256 & 256 & 96 & 130 & 162 & 0 & 0 & 0 & 0 & 0 & 19503 & 0 & 844 \\
\hline 24 & 225 & 225 & 74 & 130 & 146 & 0 & 0 & 0 & 0 & 0 & 17748 & 0 & 675 \\
\hline Total & 7428 & 7428 & 2563 & 3120 & 3787 & 1680 & 653 & 275 & 110 & 55 & 598287 & 1740 & 33062 \\
\hline
\end{tabular}

\section{B. Multi-Objective Optimization Performance Evaluation}

Figure 5 illustrates the best Pareto front out of the 20 fronts obtained by each method for the 10-unit system. It is shown that the front of NSGA-II+DLS contains the minimum cost value (\$563938) which equals to the best of the published results; the front of NSGA-II+WLS contains the minimum emission value $(33062 \mathrm{lb})$. It is seen that LSA improves the Pareto-fronts. Also, the DLS has been more effective than the WLS in the search of minimum cost, and vice versa for the search of minimum emission. Figure 6 illustrates the overall Pareto front of each method, obtained by non-dominated sorting of all the solutions on the 20 fronts. It confirms the findings of Figure 5.

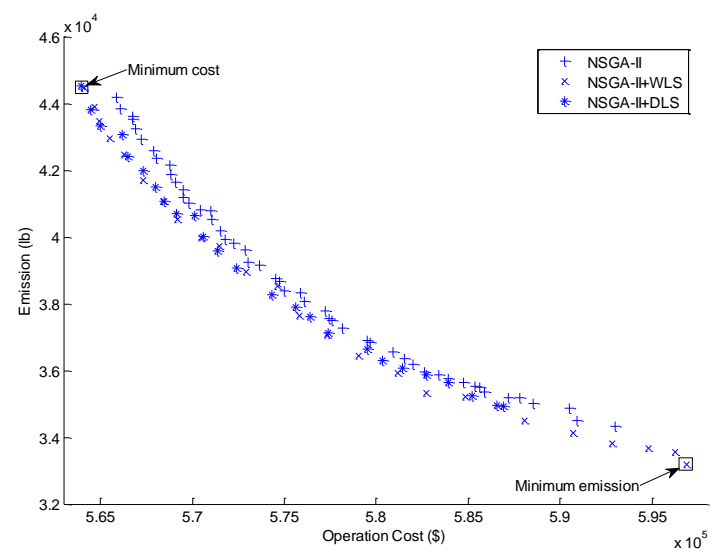

Figure 5. Best fronts out of the 20 Pareto-optimal fronts of 10-unit system

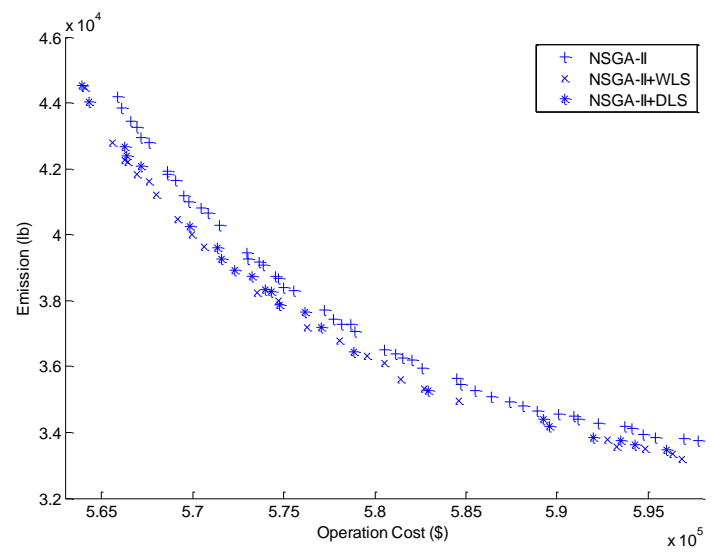

Figure 6. Overall fronts out of the 20 Pareto-optimal fronts of 10-unit system

Figures 7 illustrate the best and overall Pareto fronts of each method, obtained from all the 20 fronts on the 100-unit system, respectively. It is observed that the front of NSGAII+DLS obtains both the minimum cost and the minimum emission solutions.

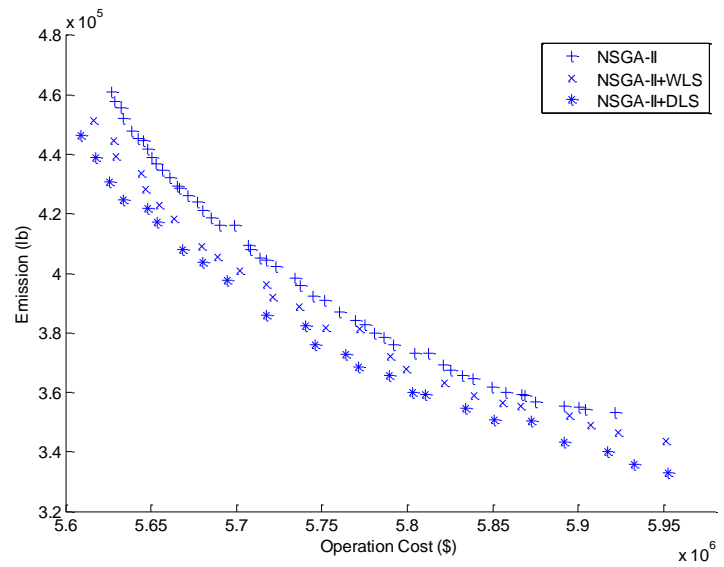

Figure 7. Best fronts out of the 20 Pareto-optimal fronts of 100-unit system

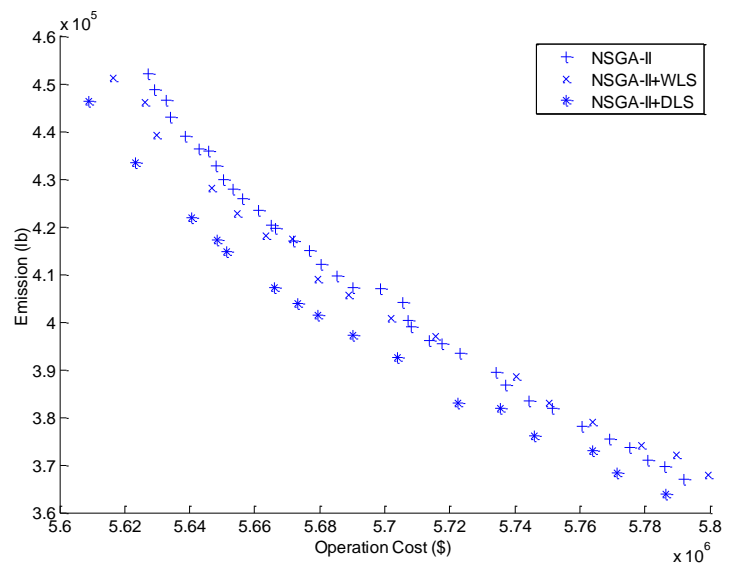

Figure 8. Overall fronts out of the 20 Pareto-optimal fronts of 100-unit system

A number of performance measures (e.g. generational distance [40], objective vector indicator [41]) have been proposed to measure the performance of multi-objective optimization algorithms. The hyper-volume is widely used in recent studies by the MOEA community. The hyper-volume is the area (volume or hyper-volume) under the dominated 
region defined by the non-dominated set. Details on computing the hyper-volume measure can be found in [41].

For each of the 20 runs of each algorithm, a hyper-volume value with the reference point at $\left[6 \times 10^{5}, 4.6 \times 10^{4}\right]$ for 10 unit system or $\left[6 \times 10^{6}, 4.6 \times 10^{5}\right]$ for 100 -unit system is calculated. Box plots of the hyper-volumes of each algorithm are shown in Fig. 9 and Table VIII summarizes the statistics of the results. It is seen that the mean and median values of MOMAs are in general higher than those of NSGA-II. In addition, MOMAs have lower standard deviations than that of NSGA-II. NSGA-II+DLS has the highest median and NSGAII+WLS has the second highest median.
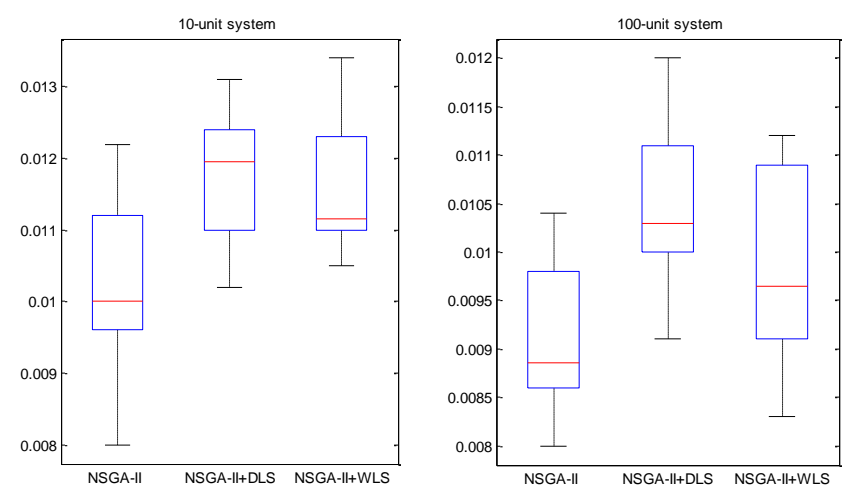

Figure 9. Box plots of the hyper-volumes of the algorithms on 10-unit system and 100-unit system

TABLE VIII. STATISTICS OF THE HYPER-VOLUME VALUES

\begin{tabular}{|l|l|l|l|l|l|l|}
\hline \multirow{2}{*}{} & \multicolumn{3}{|c|}{ 10-unit } & \multicolumn{3}{c|}{100 -unit } \\
\cline { 2 - 7 } & mean & std & median & mean & std & median \\
\hline NSGA-II & 0.0103 & 0.0012 & 0.0100 & 0.0091 & 0.0008 & 0.0089 \\
\hline $\begin{array}{l}\text { NSGA-II } \\
+ \text { DLS }\end{array}$ & 0.0118 & 0.0010 & 0.0120 & 0.0105 & 0.0008 & 0.0103 \\
\hline $\begin{array}{l}\text { NSGA-II } \\
+ \text { WLS }\end{array}$ & 0.0115 & 0.0009 & 0.0112 & 0.0098 & 0.0010 & 0.0097 \\
\hline
\end{tabular}

It is also observed that the distributions of hyper-volume values are skewed. This implies that the standard $t$-test cannot be applied for significance testing, and thus the assumptionfree Wilcoxon rank-sum tests are performed instead [42]. Table IX summarizes the $p$-values of the Wilcoxon rank-sum tests of NSGA-II versus MOMAs. In the four paired comparisons, $p$-values are generally less than or equal to 0.05 except for one case that NSGA-II+WLS versus NSGA-II on 100-unit system. The improvements of MOMAs to NSGA-II in terms of median hyper-volume values are amount to $19.5 \%$ and $9.2 \%$ for DLS, and $10.3 \%$ and $5.6 \%$ for WLS.

TABLE IX. RESULTS OF WILCOXON RANK-SUM TESTS

\begin{tabular}{|l|c|c|c|c|}
\hline \multirow{2}{*}{} & \multicolumn{2}{|c|}{10 -unit } & \multicolumn{2}{c|}{$100-$ unit } \\
\cline { 2 - 5 } & $\begin{array}{c}\text { NSGA-II } \\
+ \text { DLS }\end{array}$ & $\begin{array}{c}\text { NSGA-II } \\
+ \text { WLS }\end{array}$ & $\begin{array}{c}\text { NSGA-II } \\
+ \text { DLS }\end{array}$ & $\begin{array}{c}\text { NSGA-II } \\
+ \text { WLS }\end{array}$ \\
\hline$p$-values & 0.01 & 0.02 & 0.02 & 0.10 \\
\hline Improvement (\%) & $19.5 \%$ & $10.3 \%$ & $16.1 \%$ & $8.4 \%$ \\
\hline
\end{tabular}

\section{Unit Commitment Considering Ramp-Rate Limits}

NSGA-II+DLS is applied to solve the EUCP with ramp-rate limits. The ramp-rate limits are handled by the dynamic dispatch method proposed in [43]. The details of this method can be found in [43]. By including the ramp-rate limits, the 100 -unit system with a time horizon of 24 hours is used as one testing bed. The ramp-rate limits for the units in this system are created by duplicating the data of a 10-unit system 9 times, where the ramp-rate limits are set to $160,160,100,100,100$, $60,60,40,40$, and $40 \mathrm{MW}$ [12], respectively. The same NSGA-II parameter settings are used on both the 100-unit systems with or without the ramp-rate limits. Table $\mathrm{X}$ presents the results obtained by NSGA-II+DLS. It is seen that the generating cost and emission are increased due to the inclusion of ramp-rate characteristics into the EUCP. The efficiency and effectiveness of NSGA-II+DLS also show small differences in the computation times and final optimal costs and emissions.

TABLE X. RESULTS OF NSGA-II+DLS ON 100-UNIT UC SYSTEM WITH/WITHOUT RAMP-RATE LIMITS

\begin{tabular}{|c|c|c|c|}
\hline \multicolumn{2}{|c|}{ NSGA-II+DLS } & $\begin{array}{l}\text { Without ramp- } \\
\text { rate limits }\end{array}$ & $\begin{array}{l}\text { With ramp- } \\
\text { rate limits }\end{array}$ \\
\hline \multicolumn{2}{|c|}{ Average time (Sec) } & 4254 & 4583 \\
\hline \multirow[t]{3}{*}{ Cost (\$) } & Best & 5605918 & 5608524 \\
\hline & Average & 5611534 & 5611614 \\
\hline & Worst & 5615476 & 5617595 \\
\hline \multirow{3}{*}{$\begin{array}{l}\text { Emission } \\
\text { (lb) }\end{array}$} & Best & 329938 & 335500 \\
\hline & Average & 341065 & 341516 \\
\hline & Worst & 344560 & 351900 \\
\hline
\end{tabular}

\section{OBSERVATIONS AND DISCUSSIONS}

From the numerical results presented in Section $\mathrm{V}$, the following observations are made: 1) the local search algorithms can effectively improve the performance of NSGA-II on the EUCP, 2) the solutions obtained are comparable to published single-objective cost optimal results, 3) satisfactory multiple Pareto-optimal solutions are generated in one simulation run.

Two directions of improvement of the current work are: 1) EUCP formulation: more realistic settings, e.g. the spinning reserve cost aligning well with the electricity market where the spinning reserve is traded, and the valve point effects representing the non-linear input-output characteristics of the generation units, can be added into the cost objective function; 2) solution method design: the heuristics e.g. SA and EAs, can be applied to solve the EEDP when the valve point effects are considered, and the quantum inspired coding and mutation [44] can be introduced into NSGA-II to improve its computation efficiency.

One potential application of EUCP is to fit it into the electricity market structure considering emission trading. The UCP is an important problem with significant economical impact onto the newly deregulated electricity markets. In the simultaneous market structure such as the Pennsylvania, New Jersey, and Maryland (PJM) market of the U.S. and the British market, an independent system operator (ISO) needs to solve it to obtain the hourly market clearing prices and to determine the awards [45]. With the effort to reduce the negative trends of climate changes, the emission trading mechanism such as the European Union Emission Trading Scheme (EU ETS) permits the allocation of specified amounts of emission allowance to various industrial installations including generation units [46]. Under this scheme, it is expected that the electricity market clearing outcome will be affected by the emission allowance [47]. The proposed EUCP method might be suitable for this combined scheme as it can provide the 
multiple Pareto-optimal generation schedules to the generating company and ISO when the emission allowance is traded and amount of allowance is changed.

\section{CONCLUSIONS}

In this study, we have included the environmental objective of low emissions into the UCP. The multi-objective problem that derives is handled within the dominance scheme of optimization which leads to the identification of the Pareto fronts and sets. A multi-objective memetic algorithm is then originally designed to solve EUCP. Within the MOMA, the global exploration is done by NSGA-II and the local exploitation by one local search strategy (DLS or WLS) combined with one local search operator which dynamically turns on/off the units at the boundaries of the generation schedules. The effectiveness of the proposed MOMA is demonstrated on a 10-unit system and a 100-unit system, with a time horizon of 24 hours.

\section{ACKNOWLEDGEMENT}

The authors would like to thank the anonymous referees for their constructive comments and helpful suggestions to improve this paper.

\section{REFERENCES}

[1] D. N. Simopoulos, S. D. Kavatza, and C. D. Vournas, "Reliability Constrained Unit Commitment Using Simulated Annealing," IEEE Transactions on Power Systems, vol.21, no.4, pp. 1699 - 1706, 2006.

[2] I. G. Damousis, A. G. Bakirtzis, and P. S. Dokopoulos, "A solution to the unit-commitment problem using integer-coded genetic algorithm," IEEE Transactions on Power Systems, vol.19, no.2, pp. 1165-1172, 2004.

[3] T. Senjyu, K. Shimabukuro, K. Uezato, and T. Funabashi, "A fast technique for unit commitment problem by extended priority list," IEEE Transactions on Power Systems, vol.18, no.2, pp. 882-888, 2003.

[4] P. G. Lowery, "Generating Unit Commitment by Dynamic Programming," IEEE Transactions on Power Apparatus and Systems, vol.PAS-85, no.5, pp. 422-426, 1966.

[5] C. L. Chen and S. C. Wang, "Branch-and-Bound Scheduling for Thermal Generating Units," IEEE Transactions on Energy Conversion, vol.8, no.2, pp. 184-189, 1993.

[6] K. Y. Huang, H. T. Yang, and C. L. Huang, "A new thermal unit commitment approach using constraint logic programming " IEEE Transactions on Power Systems, vol.13, no.3, pp. 936-945, 1998.

[7] M. Carrion and J. M. Arroyo, "A computationally efficient mixed-integer linear formulation for the thermal unit commitment problem," IEEE Transactions on Power Systems, vol.21, no.3, pp. 1371-1378, 2006.

[8] A. Frangioni, C. Gentile, and F. Lacalandra, "Tighter Approximated MILP Formulations for Unit Commitment Problems," IEEE Transactions on Power Systems, vol.24, no.1, pp. 105 - 113, 2009.

[9] A. Merlin and P. Sandrin, "A New Method for Unit Commitment at Electricite De France," IEEE Transactions on Power Apparatus and Systems, vol.PAS-102, no.5, pp. 1218 - 1225, 1983.

[10]W. Ongsakul and N. Petcharaks, "Unit commitment by enhanced adaptive Lagrangian relaxation," IEEE Transactions on Power Systems, vol.19, no.1, pp. 620-628, 2004.

[11]D. N. Simopoulos, S. D. Kavatza, and C. D. Vournas, "Unit commitment by an enhanced simulated annealing algorithm," IEEE Transactions on Power Systems, vol.21, no.1, pp. 68 - 762006.

[12] T. W. Lau, C. Y. Chung, K. P. Wong, T. S. Chung, and S. L. Ho, "Quantum-Inspired Evolutionary Algorithm Approach for Unit Commitment," IEEE Transactions on Power Systems, vol.24, no.3, pp. $1503-1512,2009$.
[13]J. Valenzuela and A. E. Smith, "A Seeded Memetic Algorithm for Large Unit Commitment Problems," Journal of Heuristics, vol.8, pp. 173-195, 2002.

[14]J. Ebrahimi, S. H. Hosseinian, and G. B. Gharehpetian, "Unit Commitment Problem Solution Using Shuffled Frog Leaping Algorithm," IEEE Transactions on Power Systems, vol.26, no.2, pp. 573 - 581, 2011.

[15]Y. W. Jeong, J. B. Park, S. H. Jang, and K. Y. Lee, "A New QuantumInspired Binary PSO: Application to Unit Commitment Problems for Power Systems," IEEE Transactions on Power Systems, vol.25, no.3, pp. $1486-1495,2010$.

[16] V. S. Pappala and I. Erlich, "A Variable-Dimension Optimization Approach to Unit Commitment Problem," IEEE Transactions on Power Systems, vol.25, no.3, pp. 1696 - 1704, 2010.

[17]N. P. Padhy, "Unit Commitment -A Bibliographical Survey," IEEE Transactions on Power Systems, vol.19, no.2, pp. 1196-2005, 2004.

[18]I. J. Raglend and N. P. Padhy, "Comparison of Practical Unit Commitment Solutions," Electric Power Components and Systems, vol.36, no.8, pp. 844-863, 2008.

[19]R. Billinton and M. Fotuhi-Firuzabad, "A basic framework for generating system operating health analysis," IEEE Transactions on Power Systems, vol.9, no.3, pp. 1610-1617, 1994.

[20]M. A. Abid, "Environmental/Economic Power Dispatch Using Multiobjective Evolutionary Algorithms," IEEE Transactions on Power Systems, vol.18, no.4, pp. 1529-1537, 2003.

[21]L. F. Wang and C. Singh, "Environmental/economic power dispatch using a fuzzified multi-objective particle swarm optimization algorithm," Electric Power Systems Research, vol.77, no.12, pp. 1654-1664, 2007.

[22] J. J. Cai, X. Q. Ma, Q. Li, L. X. Li, and H. P. Peng, "A multi-objective chaotic ant swarm optimization for environmental/economic dispatch," International Journal of Electrical Power \& Energy Systems, vol.32, no.5, pp. 337-344, 2010.

[23]R. Yokoyama, S. H. Bae, T. Morita, and H. Sasaki, "Multiobjective generation dispatch based on probability security criteria," IEEE Transactions on Power Systems, vol.3, pp. 317-324, 1988.

[24]J. S. Dhillon, S. C. Parti, and D. P. Kothari, "Stochastic economic emission load dispatch," Electric Power System Research, vol.26, pp. 186197, 1993.

[25]E. Zitzler, "Two Decades of Evolutionary Multi-objective Optimisation: A Glance Back and a look Ahead," in IEEE symposium on Computational Intelligence in Multi Criteria Decision Making, Honolulu, Hawaii, USA, 2007.

[26]E. Zio, P. Baraldi, and N. Pedroni, "Optimal power system generation scheduling by multi-objective genetic algorithms with preferences," Reliability Engineering \& System Safety, vol.94, no.2, pp. 432-444, 2009.

[27]J. Xie, X. Wei, Y. Lu, and D. Gan, "Emission-constrained optimal generation scheduling incorporating equity principles," IET Generation, Transmission \& Distribution, vol.4, no.2, pp. 201-210, 2010.

[28]D. E. Goldberg, Genetic algorithms in search, optimization and machine learning. Reading, MA: Addison-Wesley, 1989.

[29]C. A. C. Coello, "A comprehensive survey of evolutionary-based multiobjective optimization techniques," Knowledge and Information Systems, vol.1, no.3, pp. 269-308, 1999.

[30]P. Moscato, "On evolution, search, optimization, genetic algorithms and martial arts: Towards memetic algorithms," Caltech, Pasadena, CA1989.

[31]N. Krasnogor and J. Smith, "A tutorial for competent memetic algorithms: Model, taxonomy, and design issues," IEEE Transactions on Evolutionary Computation, vol.9, no.5, pp. 474-488, 2005.

[32] H. Ishibuchi, T. Yoshida, and T. Murata, "Balance between genetic search and local search in memetic algorithms for multiobjective permutation flowshop scheduling," IEEE Transactions on Evolutionary Computation vol.7, no.2, pp. 204-223, 2003.

[33]M. Basu, "Economic environmental dispatch using multi-objective differential evolution," Applied Soft Computing, vol.11, pp. 2845-2853, 2011.

[34] Y. Sawaragy, H. Nakayama, and T. Tanino, Theory of multiobjective optimization. Orlando, FL: Academic Press, 1985.

[35]A. J. Wood and B. F. Wollenberg, Power Generation, Operation, and Control. New York: John Wiley \& Sons 1996.

[36] K. Deb, A. Pratap, S. Agarwal, and T. Meyarivan, "A fast and elitist multiobjective genetic algorithm: NSGA-II," IEEE Transactions on Evolutionary Computation, vol.6, no.2, pp. 182 - 197, 2002.

[37]S. A. Kazarlis, A. G. Bakirtzis, and V. Petridis, "A Genetic Algorithm Solution to the Unit Commitment Problem," IEEE Transactions on Power Systems, vol.11, no.1, pp. 83-92, 1996. 
[38]T. Senjyu, H. Yamashiro, K. Uezato, and T. Funabashi, "A unit commitment problem by using genetic algorithm based on unit characteristic classification," in IEEE Power Engineering Society Winter Meeting, 2002, vol.1, pp. 58-63.

[39] M. Moghimi Hadji and B. Vahidi, "A Solution to the Unit Commitment Problem Using Imperialistic Competition Algorithm," IEEE Transactions on Power Systems, vol.27, no.1, pp. 117-124, 2012.

[40]D. A. van Veldhuizen, "Multiobjective evolutionary algorithms: classifications, analyses, and new innovations," Graduate School of Engineering, Air Force Institute of Technology, Air University, WrightPatterson AFB, OH, 1999.

[41]E. Zitzler, L. Thiele, M. Laumanns, C. M. Fonseca, and V. G. da Fonseca, "Performance Assessment of Multiobjective Optimizers: An Analysis and Review.," IEEE Transactions on Evolutionary Computation vol.7, pp. 117-132, 2003.

[42] G. W. Corder and D. I. Foreman, Nonparametric Statistics for NonStatisticians: A Step-by-Step Approach: Wiley, 2009.

[43]C. Wang and S. M. Shahidehpour, "Effects of ramp-rate limits on unit commitment and economic dispatch," IEEE Transactions on Power Systems, vol.8, no.3, pp. 1341-1350, 1993.

[44] K. H. Han and J. H. Kim, "Quantum-inspired evolutionary algorithm for a class of combinatorial optimization," IEEE Transactions on Power Systems, vol.6, no.6, pp. 580-593, 2002.

[45]Q. Z. Zhai, X. H. Guan, and J. Cui, "Unit commitment with identical units successive subproblem solving method based on Lagrangian relaxation," IEEE Transactions on Power Systems, vol.17, no.4, pp. 1250-1257, 2002.

[46] European Commission, "EU Emissions Trading," 2005.

[47]I. Kockar, "Unit commitment for combined pool/bilateral markets with emissions trading," in Power and Energy Society General Meeting Conversion and Delivery of Electrical Energy in the 21st Century, 2008 IEEE, 2008, pp. 1-9.

Yan-Fu Li (M'11) is an assistant professor at Ecole Centrale Paris (ECP) \& Ecole Superieure d'Electricite (SUPELEC), Paris, France. Dr. Li completed his PhD research in 2009 at National University of Singapore, and went to the University of Tennessee as a research associate. His current research interests include evolutionary computing, power system reliability modeling, uncertainty modeling and analysis, and Monte Carlo simulation. He is the author of more than 30 publications, all in refereed international journals, conferences, and books. He is an invited reviewer of over 10 international journals. He is a member of IEEE.

Nicola Pedroni is an assistant professor in Nuclear Power Plants (Politecnico di Milano). He has a B.S. in Energetic Engng. (2003), a M.Sc. in Nuclear Engng. (2005) and a Ph.D. in Radiation Science and Technology (2010) (Politecnico di Milano). During his Ph.D., he visited the Department of Nuclear Science and Engineering of the MIT (2008-2009). His research focuses on the study of computational methods for the risk analysis of safetycritical systems: e.g., Monte Carlo methods for reliability estimation; theories for uncertainty representation; soft-computing techniques for regression modeling; algorithms for solving optimization problems. He is co-author of about 20 papers on international journals and 4 chapters in international books. He serves as referee of several international journals.

Enrico Zio (M'06-SM'09) has a B.S. in nuclear engineering, Politecnico diMilano,1991; a M.Sc. in mechanical engng., UCLA, 1995; a Ph.D., in nuclear engng.,Politecnico di Milano, 1995; and a Ph.D., in nuclear engng., MIT, 1998. He is the Director of the Graduate School of the Politecnico di Milano, and the full Professor of Computational Methods for Safety and Risk Analysis. $\mathrm{He}$ is the Chairman of the European Safety and Reliability Association, ESRA. He is a member of the editorial board of various international sciatic journals on reliability engineering and system safety. $\mathrm{He}$ is co-author of four international books, and more than 170 papers in international journals. He serves as referee of several international journals. 